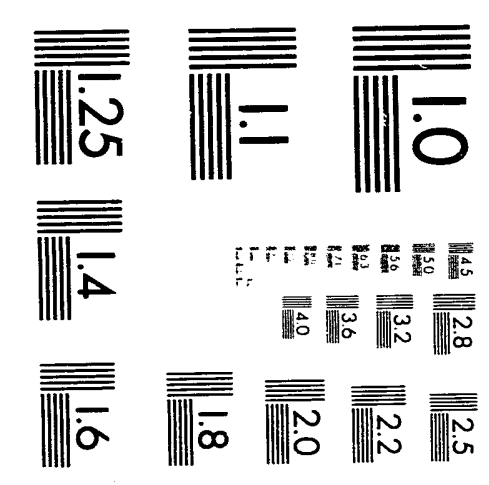



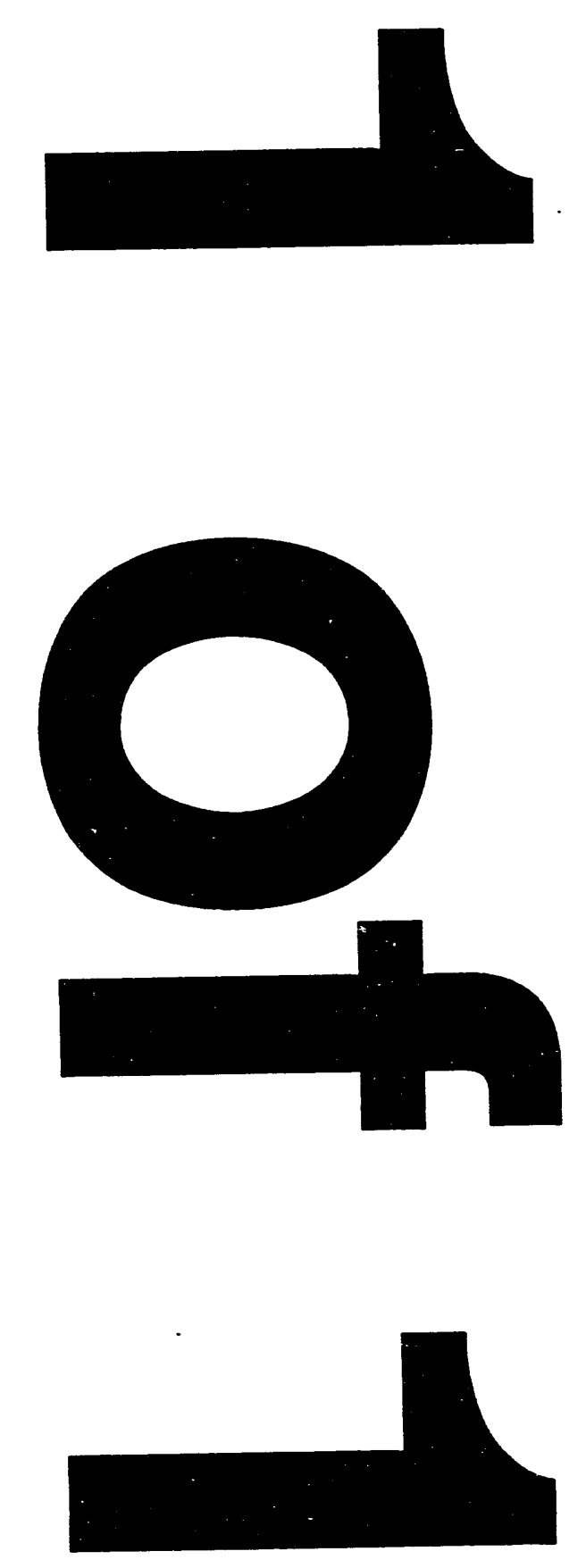


\title{
Optical Parametric Oscillator Modeling with Diffraction, Depletion, and Double Fefraction
}

\author{
Mark S. Bowers \\ Aculight Corporation \\ 40 Lake Bellevue, Suire 100 \\ Bellevue, WA 98005 \\ (206) 451-9558 \\ A. V. Smith \\ Sandia National Laboratories \\ Albuquerque, NM 87I85-5800 \\ (505)844-9166
}

\begin{abstract}
A novel, time-dependent OPO computer simulation that inclades diffaction, depletion, and double refraction is used to predict output beam profiles of pulsed OPOs.
\end{abstract}

This work was suponrted by the United

States Department of Energy under

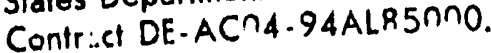

\section{DISCLAIMER}

This report was prepared as an account of work sponsored by an agency of the United States

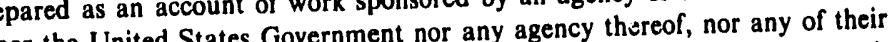
Government. Neither the United States Governmed, or assumes any legal liability or responsiemployees, makes any warranty, express or implied, or assumes any legal apparatus, product, or bility for the accuracy, completeness, or usefulness of any infe privately owned rights. Referprocess disclosed, or represents that its use would not infringe private trade name, trademark, ence herein to any specific commercial product, process, or servimply its endorsement, recommanufacturer, or otherwise does not necessarily constitute or imply its endoref. The views mendation, or favoring by the United States Government or any agency thect those of the

and opinions of authors expressed herein do not
United States Government or any agency thereof.

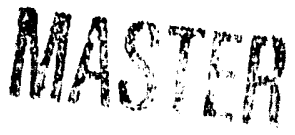




\title{
Optical Parametric Oscillator. Modeling with \\ Diffraction, Depletion, and Double Refraction
}

\author{
Mark S. Bowers \\ Aculight Corparation, 40 Lake Bellevue, Suile 100, Bellevue, Washington 98005, Ph: (206)+51-9558 \\ A. V. Smith \\ Sandia Notional Laboratories, Albuquerque, NM 87185-5800, Ph: (505)844-9166
}

\section{Introduction}

Advancement in the growth and fabrication of nonlinear materials along with continual improvements in the performance of solid-state lasers bave led to a resurgence of incerest in the development of optical parametric oscillators (OPOs). While manty experimental results have been recently reported, very little attention has boen given to the development of detailed modets to simmlate the output characteristics (such as beam quality, efficiency, and threshold) of namosecond-pumped OPOs. Such models are necessary for understanding experiments and for developing advanced $O P O$ designs that enhance the overall performance of these devices.

In this work, we describe a time-dependent model of pulsed OPOs that includes diffraction, dcpletion, und double refraction (walkoff) in the parametric amplification process. The model is used to predict output bearn profiles, beam quality, and corrversion efficiency of an injection-seeded KTP ring OPO. Predicted output beam profiles in the near and intermediate fields are in qualitative agrement with the experimental results reported in a companion paper. ${ }^{1}$ Our results show that diffaction and double refraction must $b c$ incladed in models of prised OPOs to predict realistic beam profiles.

\section{Calculational Model and Approach}

The model starts with the well-known threewave equations for optical parametric amplification with diffraction and double refraction (walkoff) in the paraxial approximation. It is restricted to propagation in uniaxial crystals and to biaxial crystals where wave propagation is in onc of the principal crystal planes. The description of the propagation of the paraxial beams through the crystal follows that given by Fleck and Feit ${ }^{2}$ with the inclusion of the nonlinear polarication terms. This formulation was used by Dreger and McIver to describe second harmonic generation in uniaxial crystals. ${ }^{3}$ The wave equation for "c-waves" differs from "o-waves" by an additional walkoff term

The temporal pulse ensvelope of the three waves is approximatod by a step-pise function For weth "step" or time slice, the nonlinear conversion process is calculated by integrating the three-wave equarions with diffraction and double refraction trough the nonlinear crystal. The time step is taken to be the OPO cavity round-uip time. A weak cw signal bean is injected into the cavity as an initial condition for the generated signal.

The calculations in time proceed as follows: a time slice of the pump is taken, and the threw-wave equations are integrated through the crystal generating signal and idlet. The three waves are then propagated to the oumpur mirror using the equations for tre-space propagation In the three-minor ring version of the model, the three waves are reflected off the output mirror, propagated around the ring inverted, and then combined with a new purop for the next rime step. Another cavity round trip is then performed This process is repeated until the pump pulse is over and the power in the three waves is negligible.

The integration of the three-wave equations through the nonlinear crystal is perfomed nsing Fourier transform techniques. 4 The diffraction and double vefraction part of the problem are anslytically extractod out by transforming into spatial frequency space. The transforms are evaluated numerically using a fast-Fourier-transform algorithm. The result of this transformation is a set of coupled ordinary tirstorder differential equations. These equations are numerically integrated through the crystal using a fifthorder Runge-Kutha algorithm.

\section{Analytical Results}

The numerical model was used to prodict the output of an injection-seded KIP ring OPO in order to compare with experiments. The experimental arrangement is similar to that reported in Ref [5] nnd is described in detail in a companion paper. ${ }^{1}$ The OPO is purmed with a frequency-doubled, injection-seeded 
$\mathrm{Nd} \cdot \mathrm{YAG}$ laser, and it is scoded with $38 \mathrm{~mW}$ of 784 nm light from a cw Ti: $\mathrm{Al}_{2} \mathrm{O}_{3}$ laser. The KTP crystal is $1 \mathrm{~cm}$ in length and is AR coated for the pump and signal wavelengths. The OPO is singty resonamt $(R=50 \%$ for the signal beam), and uses type II phase matching (o $\rightarrow+0$, pump $\rightarrow$ sigualtidler). The KTP crystal is oriented such that its ondinary polarization is perpendicular to the plane of the ring.

The model assumes a spatially Gaussian imput pump beam with a $1 / \mathrm{e}^{2}$ diametcr of $1.1 \mathrm{~mm}$ and 8 ns (FWHMM) in duration. Figure 1 shows predicled depleted pump energy fluence (intensity integrated over time) at the ourput mirror for $6 \mathrm{ml}$ of inctdent pump chergy (2.3 times above threshold). The arrow at the bottom indicates the direction the signal beam walks aff in the crystal duc to double refraction. The asymmetry in the depleted pump is dure to walkoff. The punp is depleted more in the walkoff direction. Figure 2 is the generated signal energy finence at a distance of Im from the outpur mirror. The profile is nearly circular with some slight clongation perpendicular to the plane of the ring.

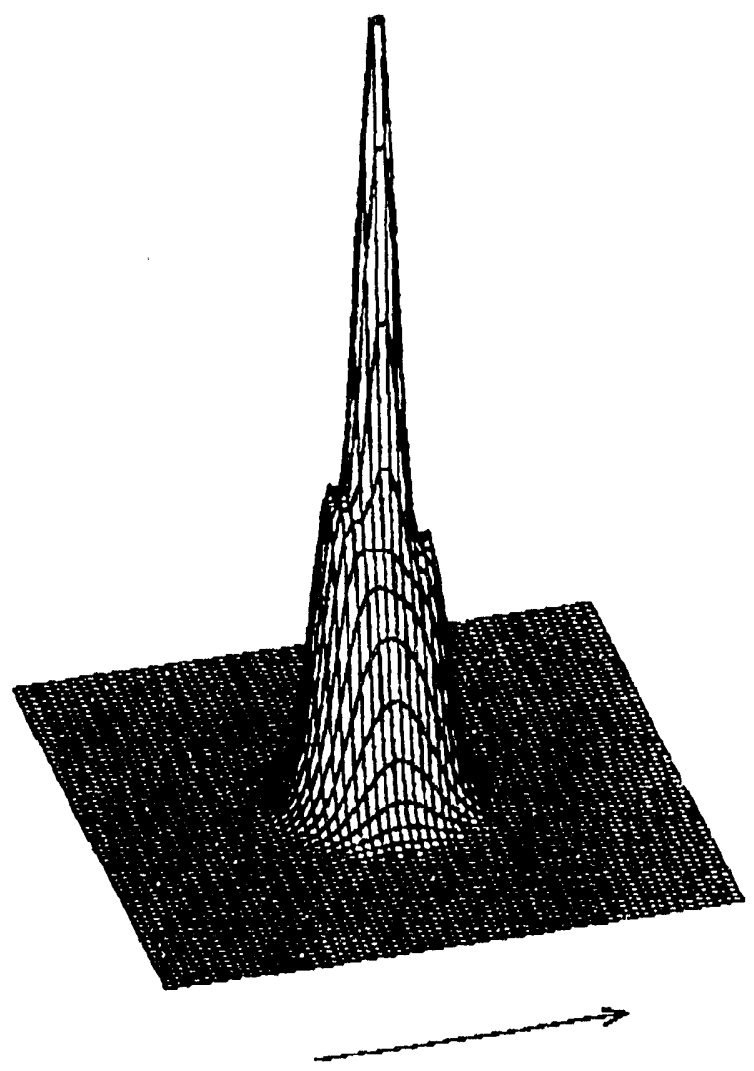

Figure 1. Predicted depleted pump energy fluence at the output mirror when pumptng 2.3 times above threshold The arrow indicates the direction the signal beam walks oft in the crustal.

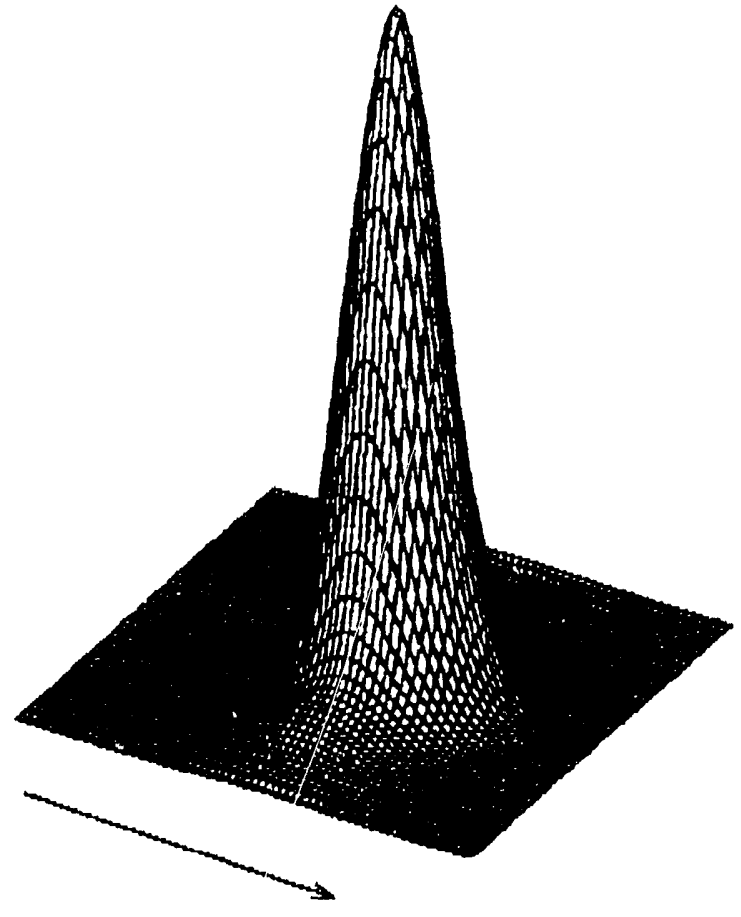

Figure 2. Outpur signal energy fluence a distonce of $1 \mathrm{~m}$ from the OFO ontput mirror. The OPO ts pumped 23 times above threshold.

Figure 3 shows the sigaal cnergy fluence at the olfut mixror for $12 \mathrm{mI}$ of incident purte (4.6 times above threshold). Because of double refraction, the signal beam is elliptical and asymmetric in the walkoff direction (in the ring plane). This signal beam at a distance of $1 \mathrm{~m}$ from the output mirror is shown in Figure 4. Compartod to Figure 2, the signal beam generated with the higher pump energy has now developed symmetric lotes on either side of the central lobe perpendicular to the walkoff direction.

At the higher purtp energy, the nonlinear drive is larger and higher angular components in the beam are able to convert. This happens preferentially in the direction perpendicular to walkoff because double tefraction limits the angular acceptance of the crystal in the walkoff direction. Thus, the beam becomes elongated perpendicular to the walkoff direction. These results are in qualitative agrecment with experimental observations. 


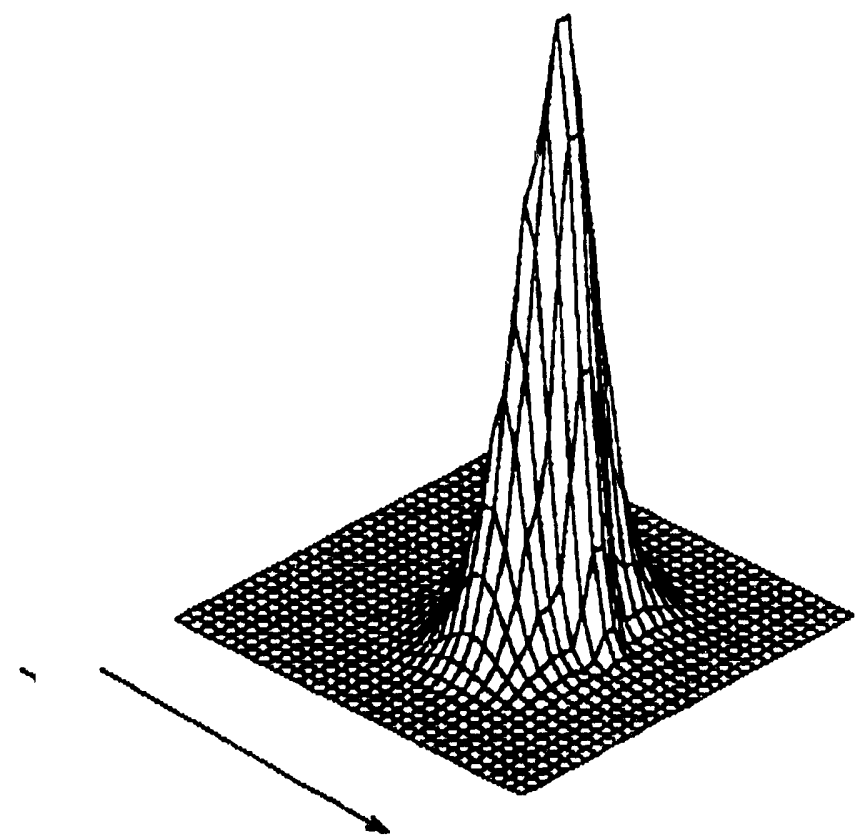

F) Figure 3. Signal energy fluence at the OPO output

$m$ mirror when pumping 4.6 times above threshold. The

ar arrow indicates the direction of walkoff in the crystal.

\section{Summary}

In summary, we have doveloped a time-dependent OPO model that inctudes diffraction, depletion, and double refiaction. Predictions of the output beam profiles of an imjection-seeded KTP ring OPO are in qualitative agrecmont with experiments. Detailed cowparisons with experiments are in progress and will be reported Our results show that diffraction and double refraction must be included in OPO models in order to predict realistic output beam profiles from these devices.

\section{References}

1. W. J. Alford and T. D. Raymond, "Title unknown at this time," submitted to

2. J. A Fleck, Jr., and M D. Feit, "Beam propagaton in uniaxial anisotropic media, $J$. Opt Soc. Am. vol. 73, pp. 920-926, July 1983.

3. M. A Dreger and J. K MeIver, "Second-harmonic generation in nonlinear, anisotrapic medium with diffraction and depletion," I. Opt. Soc. Am. B, vol. 7, pp. 776-784, May 1990.
4. S.-C. Sheng and A. E. Slegman, Nonlinear-optical calculations using fast-transform methods: Socond-barmonlc generation with deplction and diffraction," Phys. Rev. A. vol. 21, pp. 599-606, February 1980.

5. C. E. Familton and W. R. Elosenberg "SingleFrequency, Injection-seeded, KTP Ring Cavity Optical Parametric Oscrilator," in Conference of Lasers and Electro-optics, vol. 10, OSA Technical Digest Series (Optical Society of America, Washington, DC, 1992), paper CWQ3.

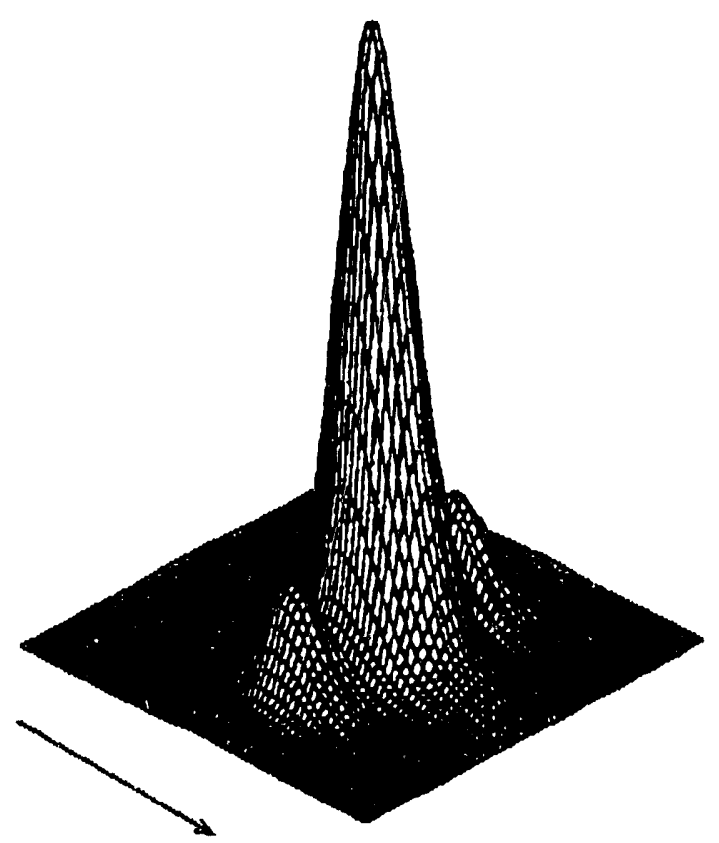

Figure 4. Output signal energy fluence after propagating Im from the output mirror for the same conditions in Figure 3. 

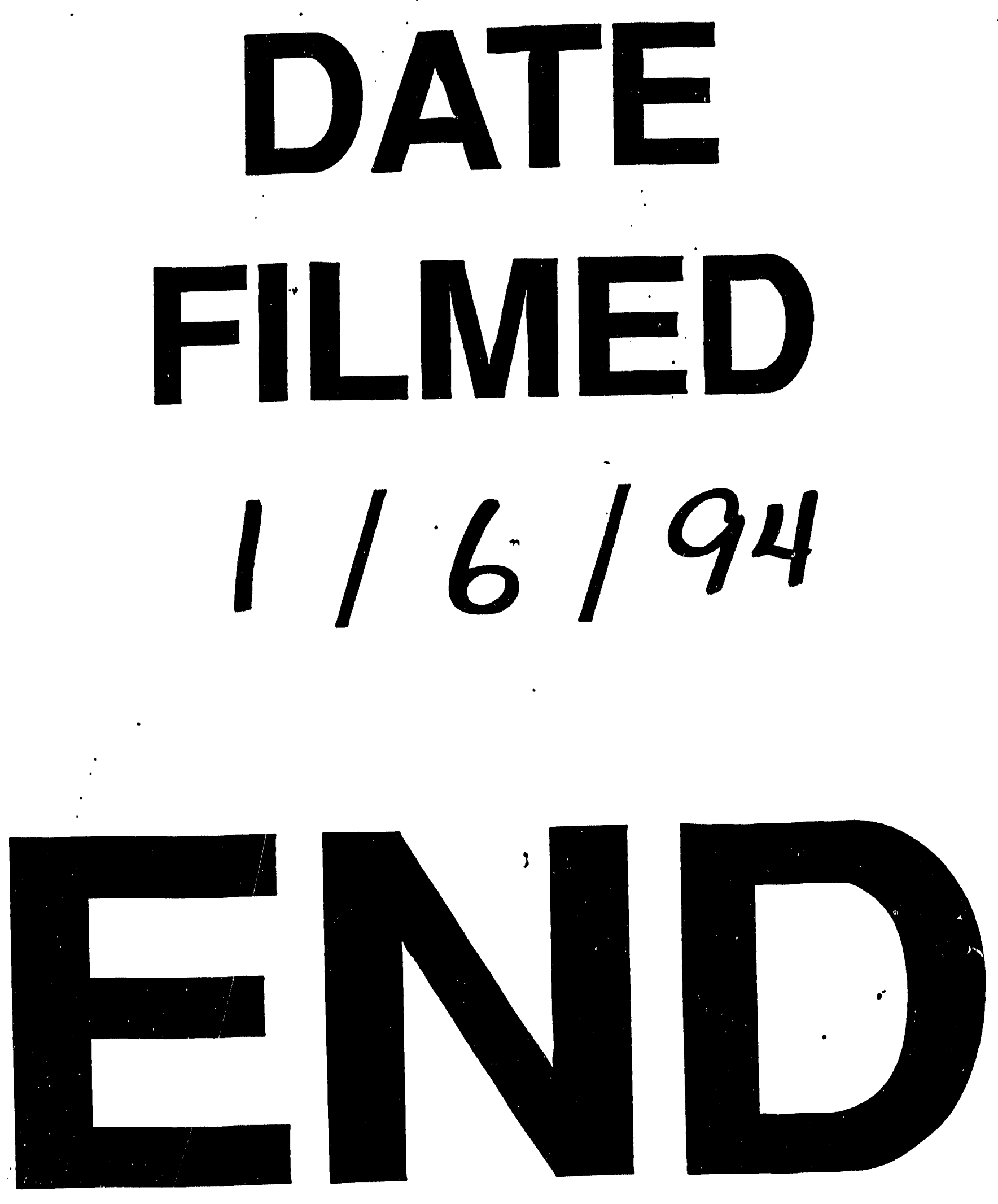
